\title{
Anatomia aplicada do ramo temporal do nervo facial: estudo do risco potencial de lesão durante a cirurgia do rejuvenescimento facial
}

\author{
Applied anatomy of the branch of the facial nerve: study of the potential risk of \\ injury during facial rejuvenation surgery
}

Maria Lídia de Abreu Silva ${ }^{1}$

José Horácio ABOUdib ${ }^{2}$

Cláudio Cardoso de

CASTRO $^{3}$

Trabalho realizado na Universidade do Estado do Rio de Janeiro (UERJ), Rio de Janeiro,

RJ, Brasil.

Artigo submetido pelo SGP (Sistema de Gestão de Publicações) da RBCP.

Artigo recebido: $12 / 9 / 2010$

Artigo aceito: 5/11/2010

\begin{abstract}
RESUMO
Introdução: $\mathrm{O}$ ramo temporal do nervo facial é um dos nervos mais comumente lesados, devido à pouca tela subcutânea que o protege a partir da sua saída da glândula parótida. Método: Vinte e cinco hemifaces de cadáveres foram dissecadas e analisadas as relações entre o ramo temporal e glândula parótida, arco zigomático, SMAS, artéria temporal superficial e músculo frontal. Resultados: Doze ramos temporais dissecados perderam a proteção da glândula parótida a uma distância de $1,7 \mathrm{~cm}$ anterior ao trago. O cruzamento do arco zigomático por dois ramos temporais foi o mais frequente. A passagem pelo arco zigomático ocorreu entre 3,2 e $3,9 \mathrm{~cm}$ posteriores à borda lateral da órbita. $\mathrm{O}$ curso do ramo temporal junto às faces profundas do SMAS e da fáscia temporoparietal, e acima da lâmina superficial da fáscia temporal profunda foi constante. $\mathrm{O}$ ramo frontal da artéria temporal superficial foi superior e sua trajetória paralela ao ramo temporal em $92 \%$ das dissecções. Conclusão: $O$ ramo temporal do nervo facial segue um plano constante ao longo da face profunda da fáscia temporoparietal e está muito superficial quando cruza o arco zigomático.
\end{abstract}

Descritores: Nervo facial. Rejuvenescimento. Fascia/anatomia \& histologia.

\begin{abstract}
Background: The temporal branch of the facial nerve is one of the nerves more commonly injured due to the scarce subcutaneous tissue that protects it from its exit at the parotid gland. Method: Twenty five cadaveric hemifaces were dissected allowing a analysis of the temporal branch and: parotid gland, zygomatic arch, SMAS, superficial temporal artery and frontal muscle. Results: Twelve temporal branches exposed at a distance $1.7 \mathrm{~cm}$ anterior to the trago. Two temporal branches crossing the zygomatic arc was the most frequent finding. This passage occurred between 3.2 to $3.9 \mathrm{~cm}$ posterior to the lateral border of the orbit. The trajectory of the temporal branch near the deep side of the SMAS and temporofacial fascia and above the superficial layer of the deep temporal fascia was constant. The frontal branch of the superficial temporal artery was superior and parallel to the nerve trajectory in $92 \%$ of the dissections Conclusion: The temporal branch follow a constant plane along the undersurface of the temporoparietal fascia and is quite superficial as it cross the zygomatic arch.
\end{abstract}

Keywords: Facial nerve. Rejuvenation. Fascia/anatomy \& histology.

\footnotetext{
1. Mestrado; Professora da Disciplina de Cirurgia Plástica - Hospital Universitário Pedro Ernesto - UERJ, Rio de Janeiro, RJ, Brasil.

2. Mestrado; Coordenador e Professor da Disciplina de Cirurgia Plástica - Faculdade de Ciências Médicas - UERJ, Rio de Janeiro, RJ, Brasil.

3. Livre Docência; Professor da Disciplina de Cirurgia Plástica - Faculdade de Ciências Médicas - UERJ, Rio de Janeiro, RJ, Brasil.
} 


\section{INTRODUÇÃO}

Com as técnicas de dissecção mais sofisticadas durante a realização da cirurgia do rejuvenescimento facial, os nervos periféricos da face tornaram-se, potencialmente sujeitos a serem lesados.

O ramo temporal do nervo facial apresenta-se numa topografia mais superficial em relação aos outros ramos do nervo facial, tornando-se, desta maneira, mais susceptível a lesões. A preservação do ramo temporal do nervo facial requer um claro entendimento do seu curso e das suas relações com o arco zigomático e com as múltiplas camadas fasciais da região zigomática e temporal.

O propósito deste estudo é analisar a anatomia cirúrgica do ramo temporal do nervo facial, detalhando o seu posicionamento nas áreas de risco potencial, a fim de prevenir a lesão deste ramo nervoso durante a cirurgia do rejuvenescimento facial.

\section{MÉTODO}

Foram realizadas dissecções anatômicas em 20 hemifaces de cadáveres formolizados e 5 hemifaces de cadáveres frescos, cujas idades oscilaram entre 20 e 70 anos (Tabela 1).

Foram realizadas incisões pré-auriculares que estendemos para cima em direção à região temporal e para baixo, contornando o ângulo da mandíbula e a margem inferior do corpo da mandíbula. O nervo facial foi exposto desde a região parotídea até o ponto onde as terminações distais do seu ramo temporal penetravam no músculo frontal.

Os seguintes aspectos foram analisados:

1. Distância da saída do ramo temporal do nervo facial de dentro da glândula parótida em relação ao trago;

2. Número de ramos nervosos cruzando o arco zigomático;

3. Relação do ramo temporal com o arco zigomático;

4. Relação do ramo temporal com o sistema músculo aponeurótico superficial da face (SMAS), fáscia temporoparietal e fáscia temporal profunda;

5. Relação do ramo temporal com a artéria temporal superficial;

6. Terminações do ramo temporal (Apêndice I).

Tabela 1 - Distribuição dos cadáveres estudados conforme sexo e cor.

\begin{tabular}{l|c|c|c|c|c|c}
\hline \multirow{2}{*}{ Grupo Étnico } & \multicolumn{4}{|c|}{ Sexo } & \multicolumn{2}{c}{ Total } \\
\cline { 2 - 7 } & \multicolumn{3}{|c|}{ Masculino } & \multicolumn{2}{c|}{ Feminino } & \multicolumn{2}{c}{} \\
\cline { 2 - 7 } & N & \% & N & \% & N & $\%$ \\
\hline Branco & 8 & 32,0 & 2 & 8,0 & 10 & 40,0 \\
\hline Não Branco & 14 & 56,0 & 1 & 4,0 & 15 & 60,0 \\
\hline Total & 22 & 88,0 & 3 & 12,0 & 25 & 100,0 \\
\hline
\end{tabular}

\section{RESULTADOS}

Distância da saída do ramo temporal do nervo facial de dentro da glândula parótida em relação ao trago

Encontrou-se uma variação de 1,4 a 2,1 cm (Gráfico 1), com 14 ramos dissecados (56\%), exteriorizando-se a uma distância média de $1,7 \mathrm{~cm}$ do trago, com desvio padrão de $0,155 \mathrm{~cm}$ (Figuras 1 e 2).

\section{Número de ramos nervosos cruzando o arco zigomático}

Os diferentes padrões de anastomoses entre os ramos da divisão temporofacial do nervo facial originaram cinco variações mais frequentes na disposição destas conexões durante a sua passagem pelo arco zigomático (Tabela 2), sendo o achado mais frequente ( $48 \%$ das dissecções) o cruzamento pelo arco zigomático de dois ramos temporais do nervo facial sem a ocorrência de anastomoses com o ramo zigomático (Figuras 3 a 7).

\section{Relação do ramo temporal com o arco zigomático}

Para se localizar o ponto de passagem do ramo temporal do nervo facial sobre o arco zigomático, foi traçada uma linha

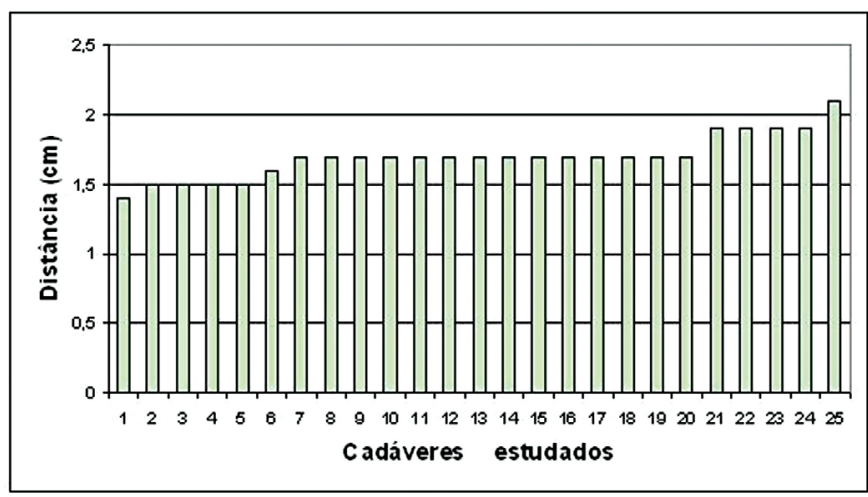

Gráfico 1 - Distâncias aferidas entre o ponto de saída do ramo temporal de dentro da glândula e o trago.

Tabela 2 - Número de ramos nervosos cruzando o arco zigomático.

\begin{tabular}{c|c|c}
\hline $\begin{array}{c}\mathbf{N}^{\mathbf{0}} \text { de ramos nervosos } \\
\text { cruzando o arco zigomático }\end{array}$ & $\mathbf{N}^{\mathbf{0}}$ de hemifaces dissecadas & $\mathbf{\%}$ \\
\hline 1 & 2 & 8,0 \\
\hline 2 & 12 & 48,0 \\
\hline 3 & 4 & 16,0 \\
\hline 4 & 2 & 8,0 \\
\hline Vários & 5 & 20,0 \\
\hline Total & 25 & 100,0 \\
\hline
\end{tabular}




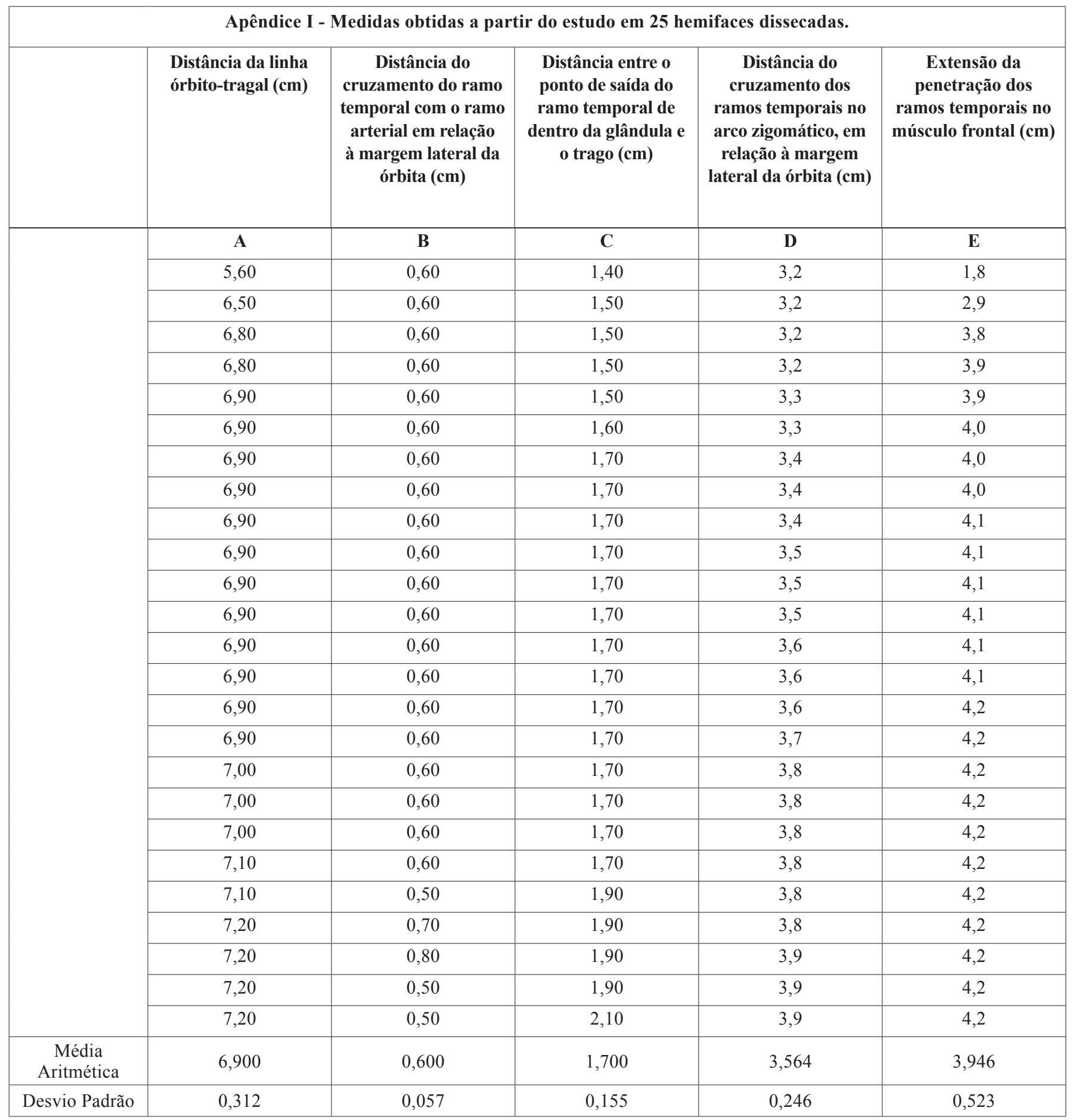

Valores, em centímetro, obtidos a partir das medidas dos comprimentos encontrados nas relações entre as seguintes estruturas anatômicas: $\boldsymbol{A}$ - distância obtida a partir de uma linha que une o trago à parede lateral da órbita, no nível do ligamento palpebral

lateral, linha órbito-tragal; $\boldsymbol{B}$ - distância entre a margem lateral da órbita, no nível da linha, unindo o ligamento palpebral

lateral à espinha da hélice, e o ponto onde ocorre o cruzamento dos ramos nervosos temporais distais com os ramos distais da artéria temporal superficial; $\boldsymbol{C}$ - distância entre o ponto de saída do ramo temporal, do interior da glândula parótida, e o trago;

$\boldsymbol{D}$ - distância entre a margem lateral da órbita, no nível da linha órbito-tragal, e o ponto onde o ramo temporal cruza o arco zigomático; $\boldsymbol{E}$ - extensão da penetração dos ramos temporais terminais na face profunda do músculo frontal a partir da altura do ligamento palpebral lateral. 


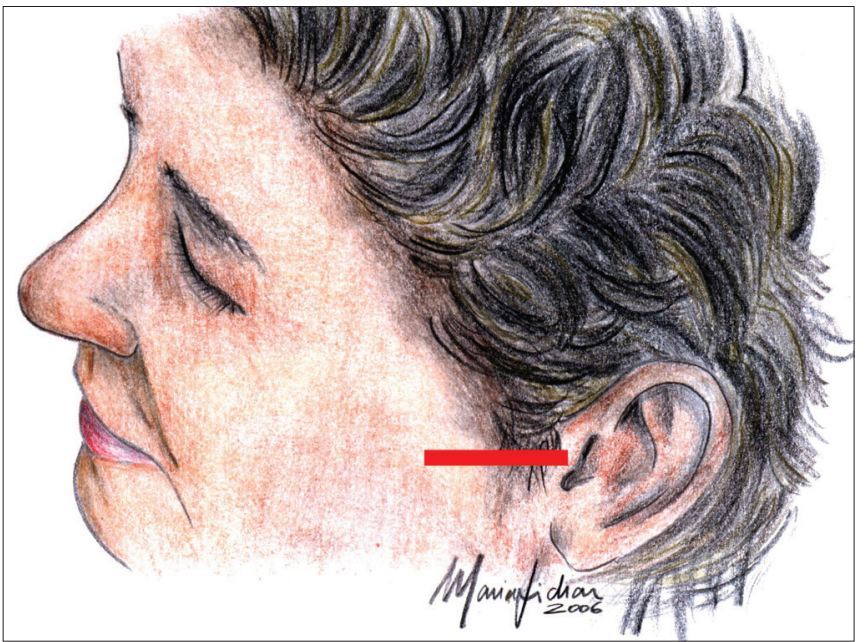

Figura 1 - Linha vermelha representa distância aferida entre o trago e o ponto onde o ramo temporal perde a proteção da glândula parótida.

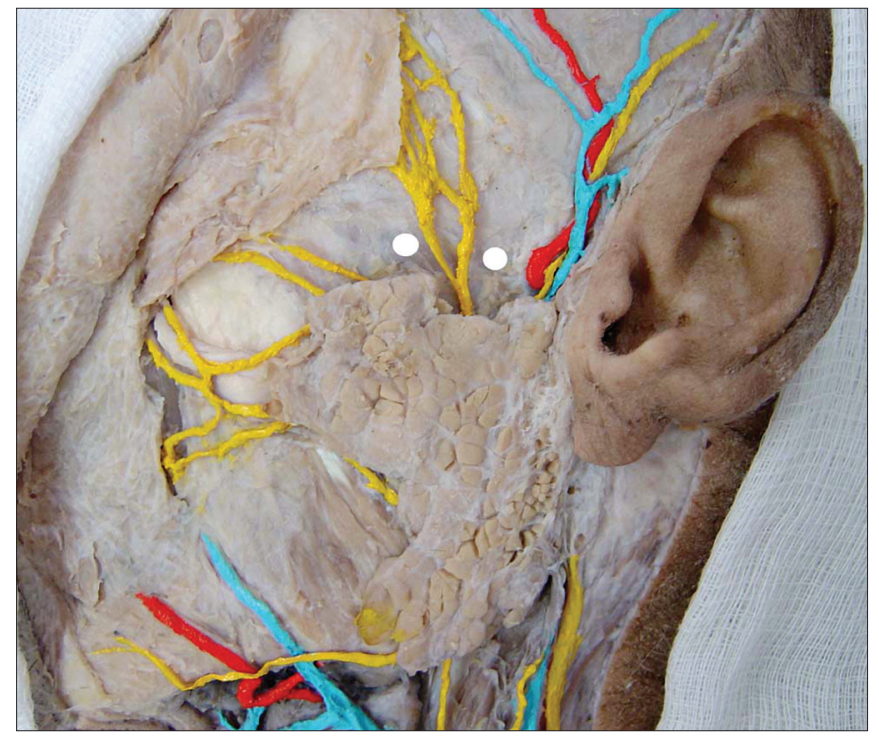

Figura 2 - Visão panorâmica da região parotídea mostra a glândula parótida protegendo o tronco nervoso principal e as divisões cervicofacial e temporofacial. As partes mais distais do nervo estão fora da proteção da glândula e correm risco durante uma ritidoplastia. Pontos brancos marcam o arco zigomático. Cadáver formolizado.

reta unindo o trago à parede lateral da órbita, no nível do ligamento palpebral lateral, chamada de linha órbito-tragal (Figura 8). Verificou-se que o cruzamento do ramo temporal sobre o arco zigomático ocorria entre 3,2 a $3,9 \mathrm{~cm}$ posteriores à margem lateral da órbita, no nível da linha órbito-tragal (Gráfico 2). O trecho da passagem do ramo nervoso sobre o arco zigomático corresponde ao seu terço médio. A distância média para esta relação anatômica foi de $3,6 \mathrm{~cm}$ e o desvio padrão foi de $0,224 \mathrm{~cm}$.

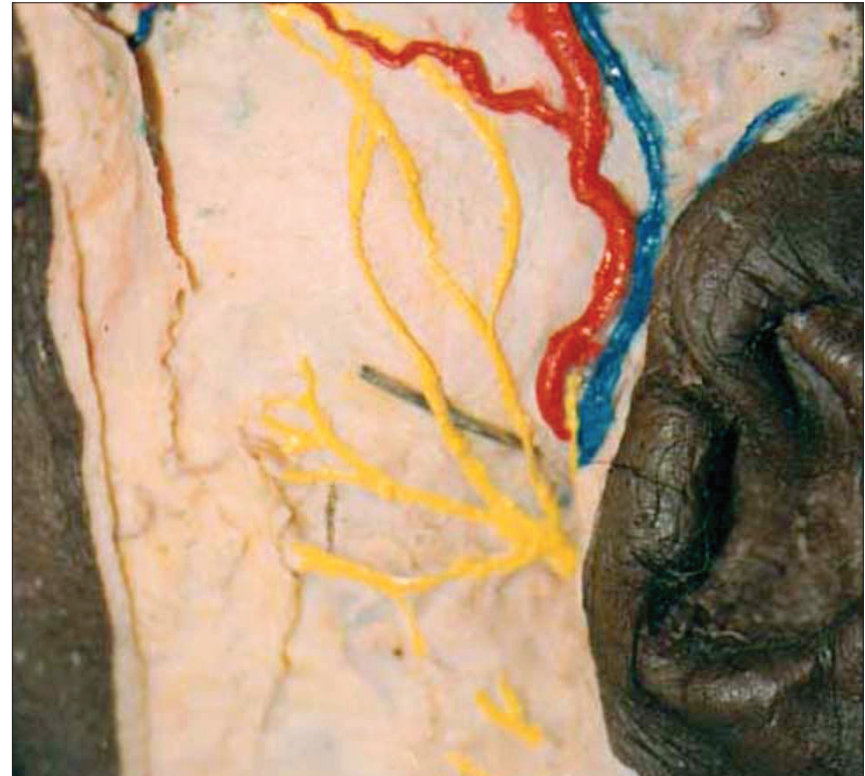

Figura 3 - Em 12 hemifaces dissecadas (48\%), dois ramos temporais cruzam o arco zigomático (marcado com agulha), $e$ atingem o músculo frontal após a ocorrência de anastomoses entre eles. Ausência de anastomose com o ramo zigomático. Cadáver formolizado.

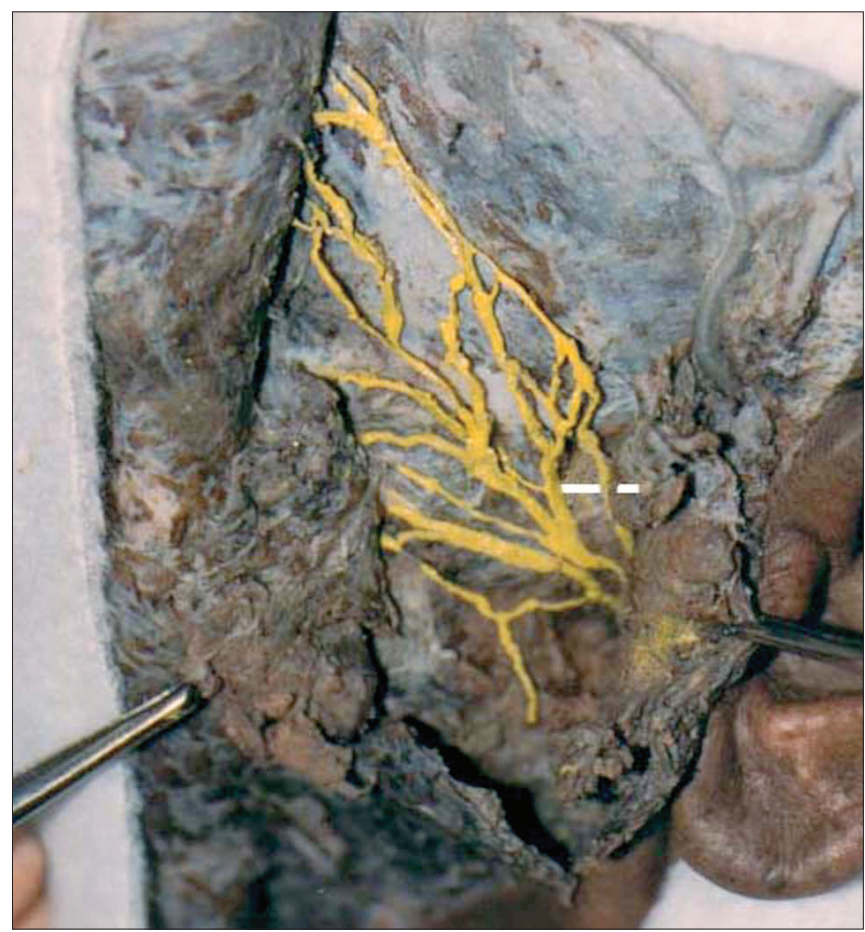

Figura 4 - Em cinco hemifaces dissecadas (20\%), vários ramos temporais cruzam o arco zigomático (marcado em branco) sob a forma de uma rede anastomótica complexa e assim se mantêm até entrarem no músculo frontal. Ocorre anastomose com o ramo zigomático. Glândula parótida rebatida por pinças. Cadáver formolizado. 


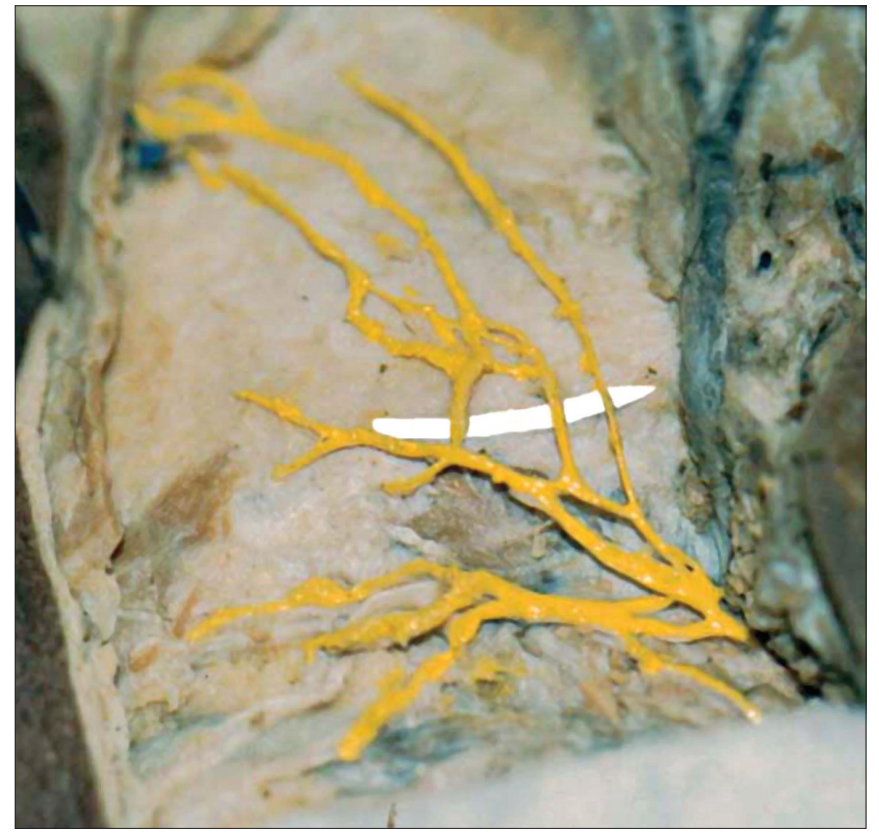

Figura 5 - Em quatro hemifaces dissecadas (16\%), três ramos cruzam o arco zigomático (marcado em branco), e apresentam anastomoses entre si e com o ramo zigomático, para alcançar o músculo frontal sob a forma de um pequeno plexo. Cadáver formolizado.

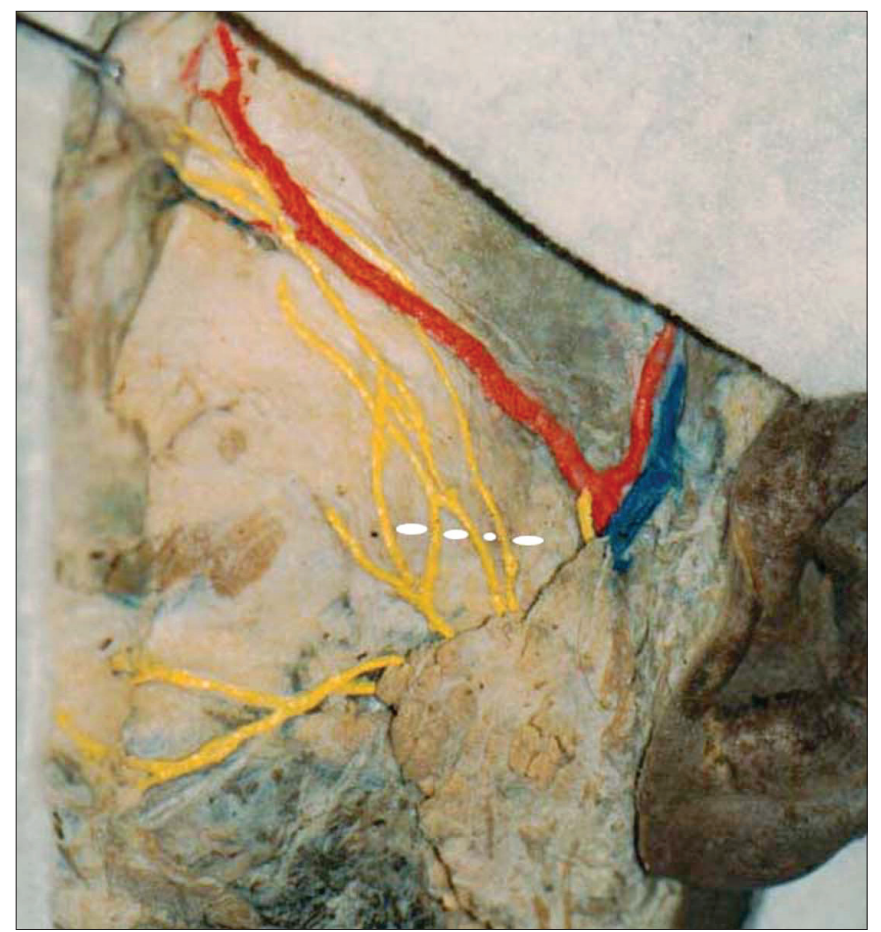

Figura 6 - Em duas hemifaces dissecadas (8\%), quatro ramos temporais cruzam o arco zigomático (marcado em branco), $e$ apresentam anastomoses entre si até alcançarem o músculo frontal . Cadáver formolizado.

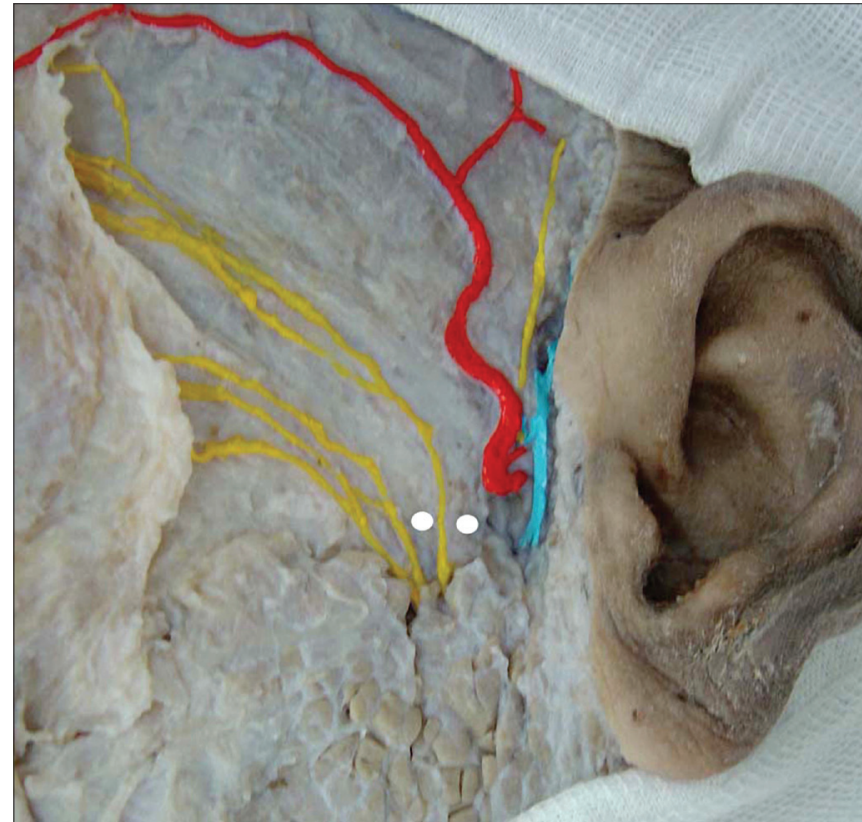

Figura 7 - Em duas hemifaces dissecadas (8\%), apenas um ramo temporal atravessa o arco zigomático (marcado em branco), e segue até o músculo frontal, quando se divide em pequenos ramos que irão penetrar no músculo. Notar o ramo frontal da artéria temporal superficial paralela e superior a curso do nervo temporal. Cadáver formolizado.

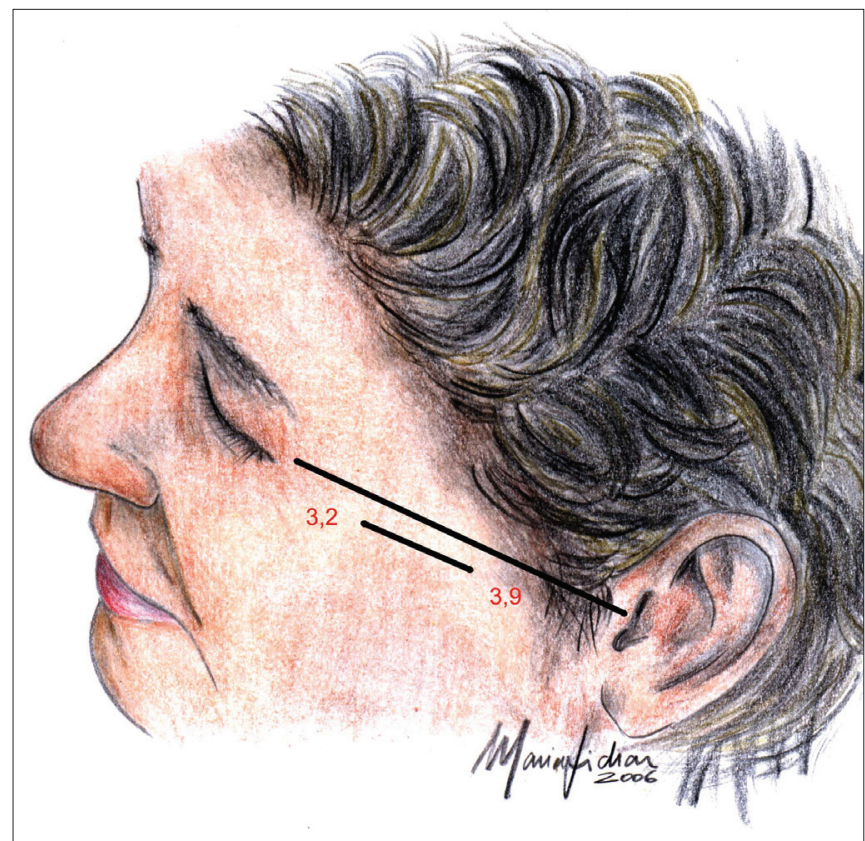

Figura 8 - Ilustração mostra a linha órbito-tragal (linha maior) que resulta da união de dois pontos que ligam o trago à parede lateral da órbita na altura do ligamento palpebral lateral. $O$ ramo temporal passa sobre este marco ósseo entre 3,2 e 3,9 cm posteriores à parede lateral da órbita (linha menor), o que corresponde ao terço médio do arco zigomático. 


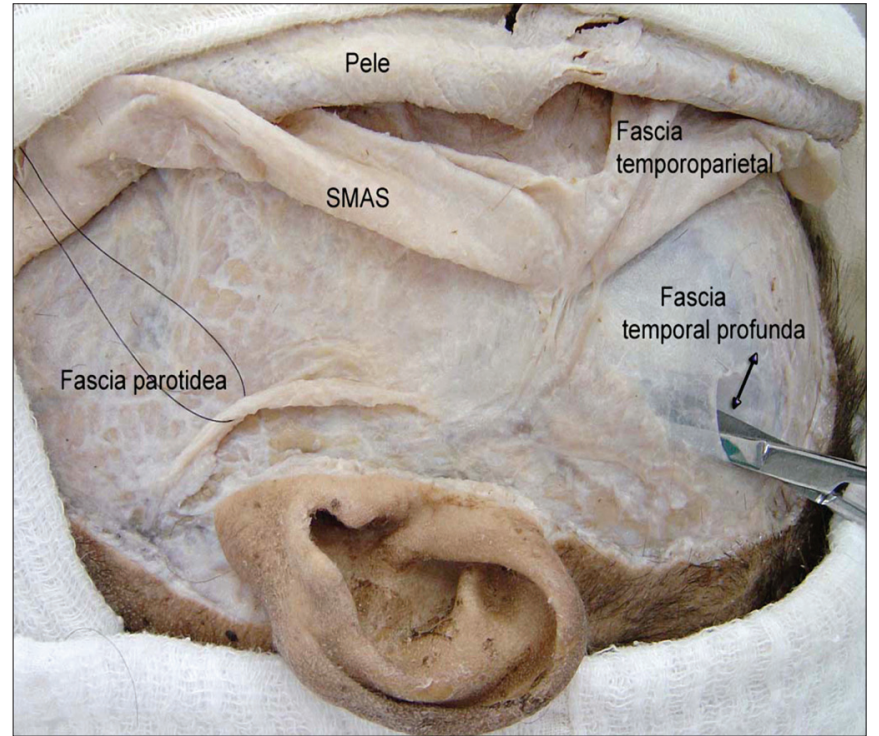

Figura 9-SMAS e sua extensão cefálica, fáscia temporoparietal ou fáscia temporal superficial estão rebatidos e permitem uma visão panorâmica da fáscia parotídea e do tecido areolar frouxo, que separa a fáscia temporoparietal da fáscia temporal profunda. Tesoura posicionada entre a lâmina superficial da fáscia temporal profunda e o tecido areolar frouxo (que contém o nervo temporal e a artéria temporal superficial) indica plano de dissecção cirúrgica seguro. Cadáver formolizado.

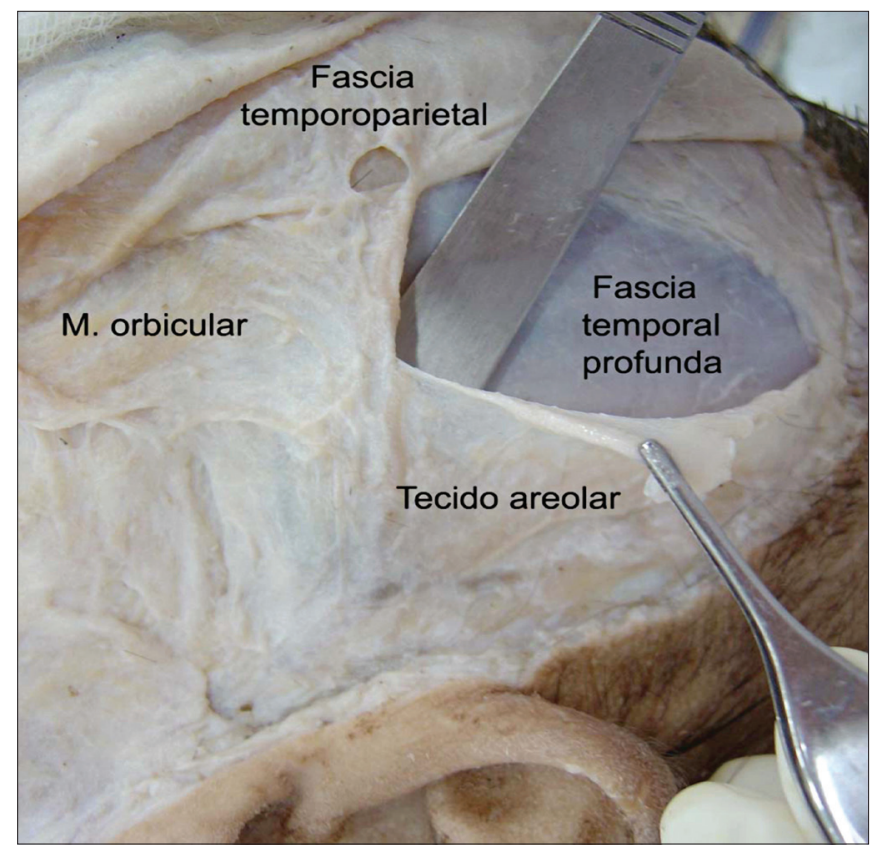

Figura 10 - Camadas fasciais da região temporal em cadáver formolizado. A camada de tecido areolar, denominada plano subaponeurótico, localiza-se entre a fáscia temporoparietal (fáscia temporal superficial) e a fáscia temporal profunda. Este plano tem um grau de espessura que permite a dissecção diretamente acima da fáscia temporal profunda mais facilmente do que ao longo da fáscia temporoparietal, onde o ramo temporal cursa.

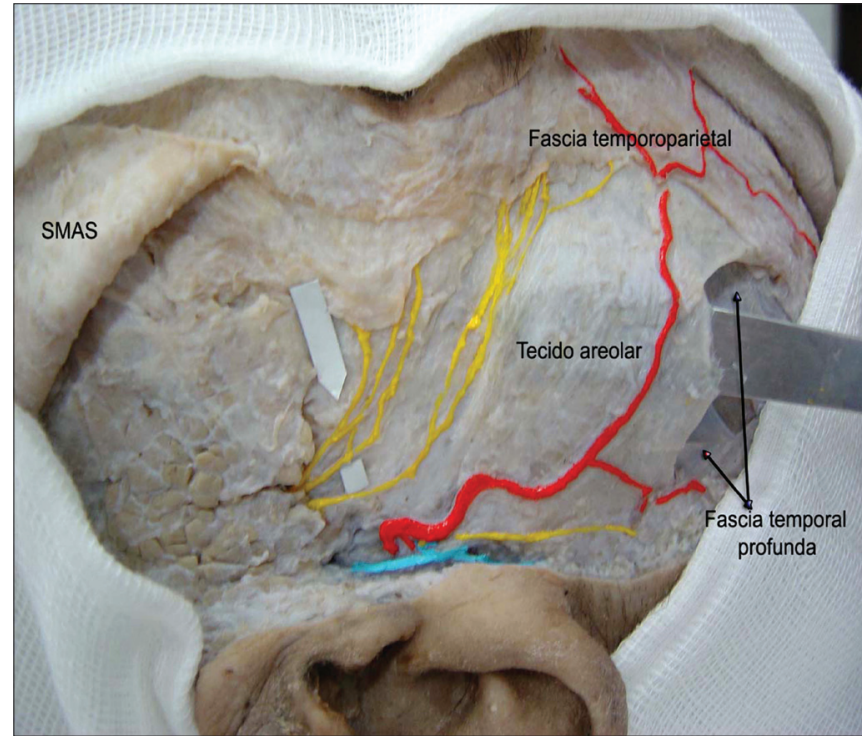

Figura 11 - A fáscia temporoparietal (fáscia temporal superficial) representa uma continuação do SMAS acima do arco zigomático. Essa fáscia não está em contato direto com o periósteo do arco

zigomático. O ramo temporal repousa na face profunda da fáscia temporoparietal e está separado do arco zigomático pela fáscia temporal profunda e pelo tecido areolar. Arco zigomático identificado por seta branca. Cadáver formolizado.

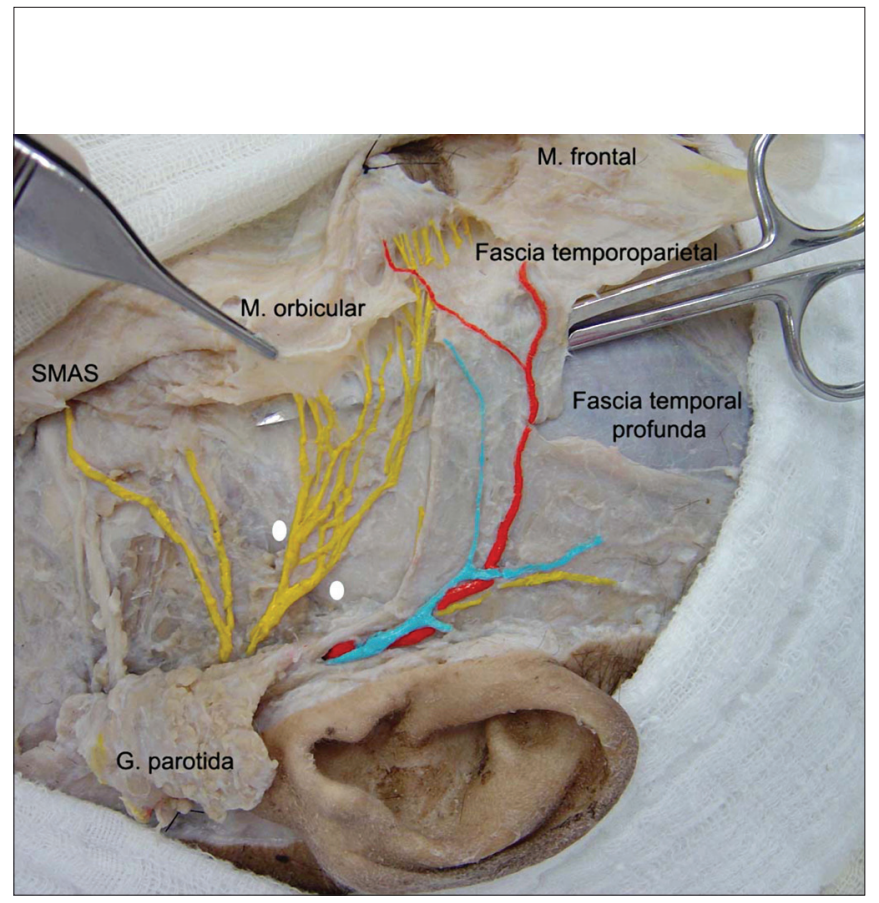

Figura 12 - O nervo temporal, que cursa junto à face profunda da fáscia temporoparietal (rebatida), é superficial quando cruza o arco zigomático (pontos brancos) e está frouxamente aderido às camadas fasciais adjacentes. Tesoura posicionada acima da lâmina superficial da fáscia temporal profunda. Cadáver formolizado. 


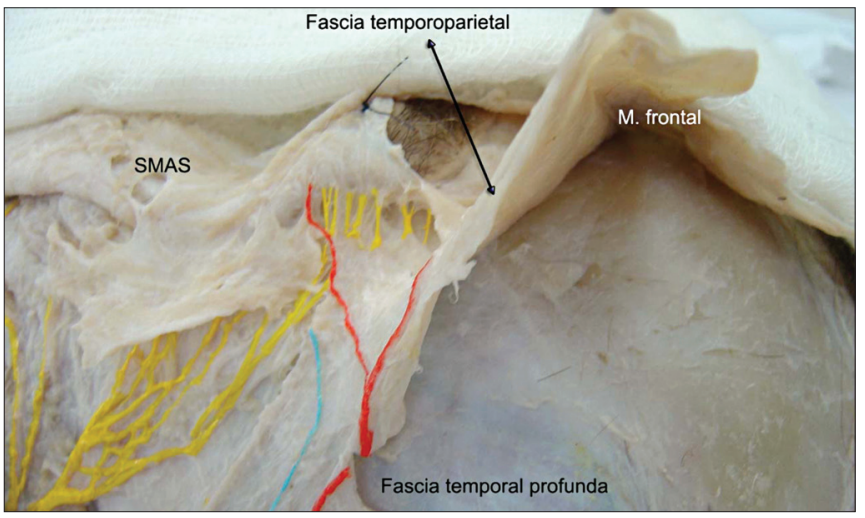

Figura 13 - Fáscia temporal profunda imediatamente acima do músculo temporal. Nervo temporal aparece saindo da divisão temporofacial e com curso em direção à região frontal. Cruza o arco zigomático em seu terço médio e se posiciona imediatamente abaixo da fáscia temporoparietal e acima da lâmina superficial da fáscia temporal profunda. Notar o curso da artéria temporal superficial,

paralelo e superior ao ramo temporal. Cadáver formolizado.

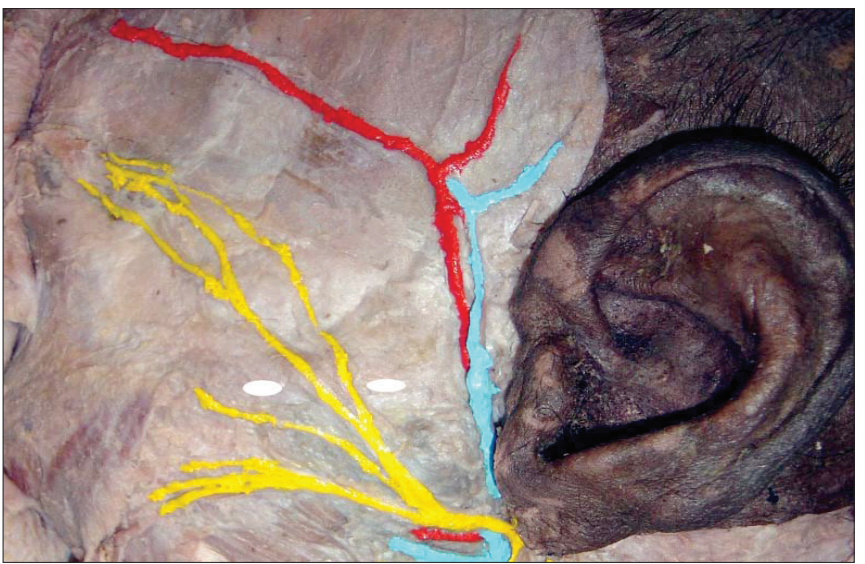

Figura 14 - Ramo frontal da artéria temporal superficial, em cadáver formolizado, apresenta curso superior e paralelo aos ramos temporais do nervo facial. Arco zigomático marcado por pontos brancos.

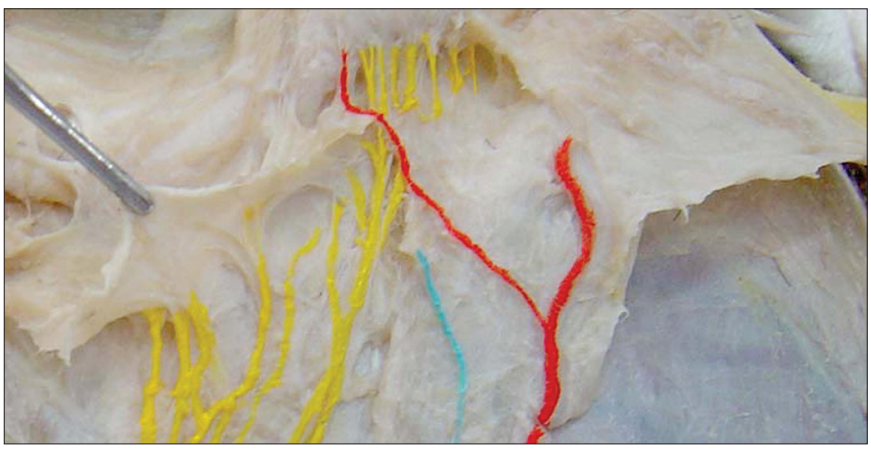

Figura 15 - Penetração dos ramos nervosos temporal e zigomático na face profunda dos músculos frontal e orbicular, sob a forma de um fino leque. Notar cruzamento de ramo arterial proveniente do ramo frontal da artéria temporal superior e ramos nervosos terminais, rente ao local de penetração do nervo no músculo frontal. Cadáver formolizado.

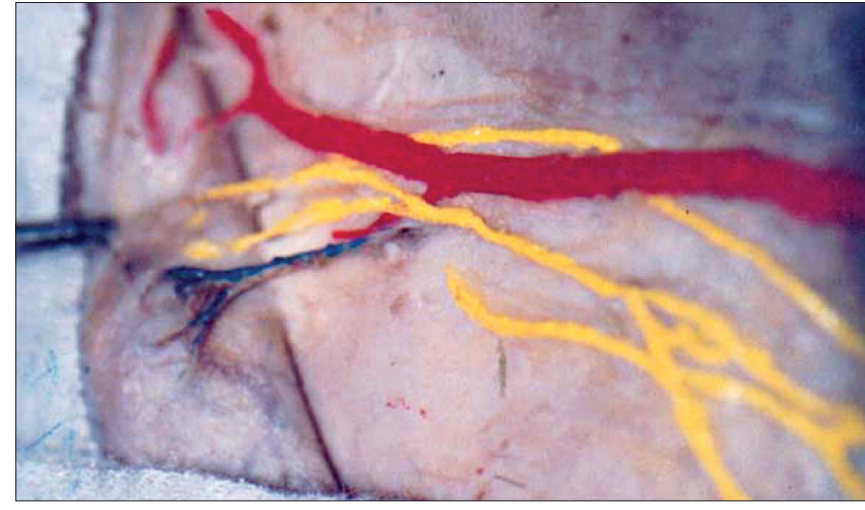

Figura 16 - Íntima relação entre os ramos nervosos temporais e arteriais terminais, na margem lateral do músculo frontal. Notar a presença da "veia inominada", comunicante entre as veias superficiais e profundas do crânio. Cadáver formolizado.

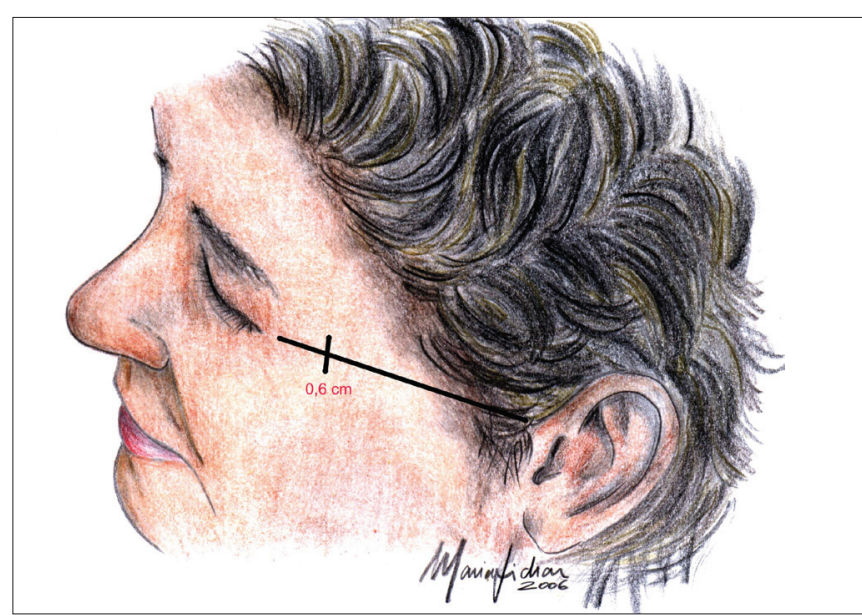

Figura 17 - Ilustração mostra linha utilizada para padronizar a aferição da distância em que o ramo nervoso e o ramo arteial se cruzam. Linha une o ligamento palpebral lateral à espinha da hélice. Seta assinala distância média de 0,6 cm a partir da margem lateral da órbita.

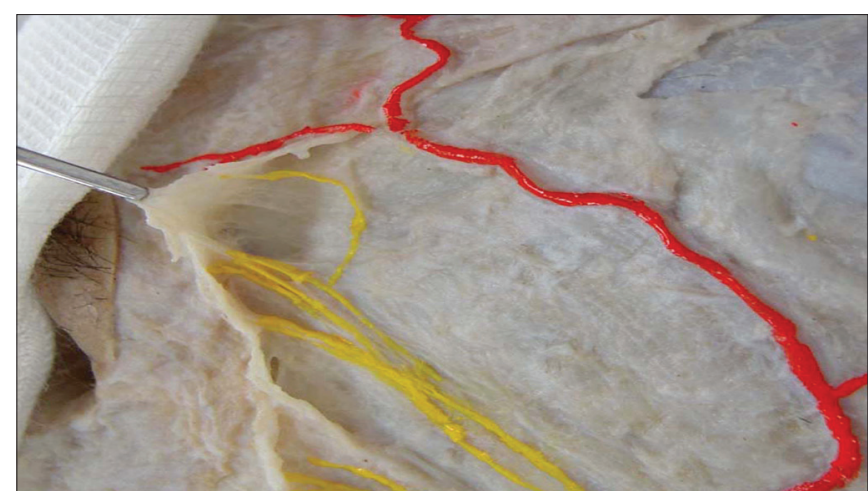

Figura 18 - Ramos temporais terminais penetram na face profunda dos músculos orbicular e frontal. Notar ramo arterial descendente misturando-se aos ramos nervosos temporais terminais na margem lateral da órbita. Cadáver formolizado. 


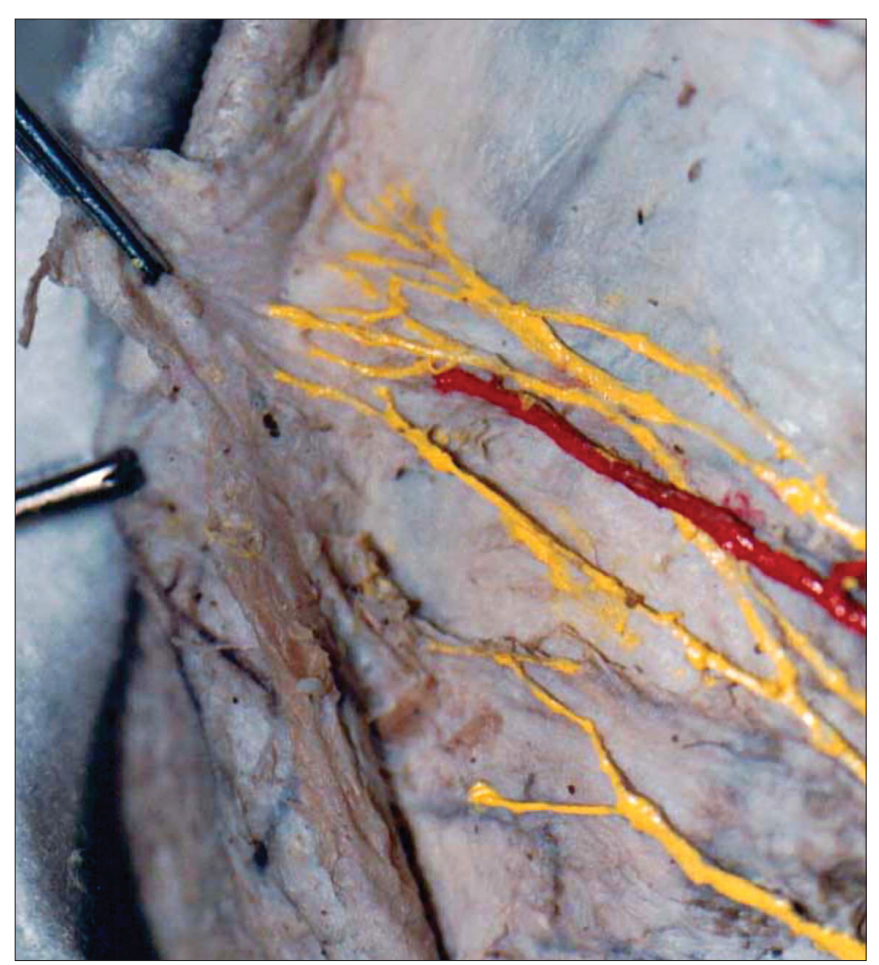

Figura 19 - Ramos nervosos temporais terminais penetram na face profunda do músculo frontal. Cadáver formolizado.

\section{Relação do ramo temporal com o SMAS, fáscia temporoparietal e fáscia temporal profunda}

Observou-se, em todas as dissecções, o trajeto do ramo temporal junto à face profunda do SMAS e fáscia temporoparietal, e acima do folheto superficial da fáscia temporal profunda (Figuras 9 a 13).

\section{Relação do ramo temporal com a artéria temporal superficial}

A artéria temporal superficial dividiu-se nos ramos anterior e posterior sempre após cruzar o arco zigomático. A relação do ramo frontal da artéria temporal superficial com o ramo temporal do nervo facial mostrou-se constante em $92 \%$ das dissecções ( 23 hemifaces): o curso da artéria foi sempre superior e paralelo ao curso do nervo (Figura 14).

Ao nível da borda ínfero-lateral do músculo frontal, o ramo frontal da artéria temporal superficial ofereceu, em todas as dissecções, um ramo descendente para o músculo frontal que coincidia com o sítio de penetração do nervo neste músculo. Este ramo arterial apresentou íntima relação com os ramos terminais do nervo temporal ao ser "abraçado" pelos ramos nervosos imediatamente antes deles penetrarem no músculo frontal (Figuras 15 e 16).

A relação anatômica entre estas duas estruturas ocorreu em $80 \%$ das dissecções (20 hemifaces) a uma distância média de $0,6 \mathrm{~cm}$ da borda lateral da órbita, ao nível da linha que une o

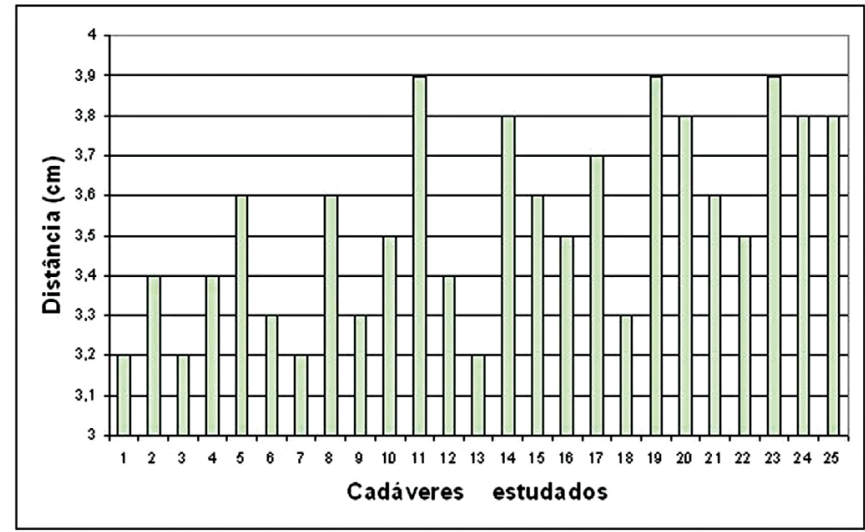

Gráfico 2 - Distância do cruzamento do ramo temporal em relação à parede lateral da órbita ao nível da linha órbito-tragal.

ligamento palpebral lateral à espinha da hélice (Figura 17).

\section{Modelo das terminações nervosas do ramo temporal}

Apurou-se que os filetes nervosos terminais penetravam no músculo frontal, profundamente em sua face interna, numa extensão que variou 1,5 a $4,2 \mathrm{~cm}$ verticalmente superior ao ligamento palpebral lateral (Figuras 18 e 19).

\section{DISCUSSÃO}

Após emergir da glândula parótida $1,7 \mathrm{~cm}$ anterior ao trago, o ramo temporal do nervo facial passa pelo arco zigomático entre 3,2 e $3,9 \mathrm{~cm}$ posterior à borda lateral da órbita, ao nível da linha órbito-tragal, o que corresponde ao terço médio do arco zigomático. Observou-se esta constância anatômica em todas as peças dissecadas. Os trabalhos de Correia \& Zani ${ }^{1}$, Mitz \& Peyronie ${ }^{2}$, Baker \& Conley ${ }^{3}$, Ozresky et al. ${ }^{4}$, Hinderer et al. ${ }^{5}$, Psillakis et al. ${ }^{6}$, Stuzin et al. ${ }^{7}$, Caix et al. ${ }^{8}$, Faivre \& Faivre ${ }^{9}$, do mesmo modo, enfatizam a vulnerabilidade do ramo temporal ao nível do terço médio do arco zigomático.

Observou-se que o nível da profundidade dos nervos temporais sobre o arco zigomático foi proporcional à quantidade de tecido adiposo apresentado pelo cadáver em estudo. Cadáveres magros e de idosos praticamente não apresentavam nenhum tecido adiposo envolvendo o nervo, tornandoos, desta forma, mais vulneráveis a lesões.

A partir dos estudos de Correia \& Zani ${ }^{1}$, Mitz \& Peyronie ${ }^{2}$, Psillakis et al. ${ }^{6}$, Stuzin et al. ${ }^{7}$, Faivre \& Faivre ${ }^{9}$ Loeb $^{10}$, Zani et al. ${ }^{11}$, pode-se confirmar nas dissecções realizadas que, acima do arco zigomático, a fáscia temporoparietal representa a extensão cefálica do SMAS e está em continuidade com a gálea aponeurótica superiormente e o músculo frontal anteriormente, porém apresenta-se com uma espessura muito fina, aumentando o risco potencial de lesão do ramo temporal 
no caso da dissecção fascial a este nível. Comprovou-se que, após sair da glândula parótida, o ramo temporal cursa imediatamente abaixo do SMAS e assim continua durante sua passagem sobre o terço médio do arco zigomático. Ultrapassando este marco anatômico, constatou-se em todas as hemifaces estudadas que o ramo temporal passa a cursar sobre o folheto superficial da fáscia temporal profunda e permanece abaixo da fáscia temporoparietal (SMAS), mantendose neste plano até penetrar no músculo frontal ao nível do rebordo orbitário superior. Este é um importante achado: o nervo temporal sempre cursa em um plano anatomicamente previsível e constante. As observações apresentadas aqui estão em concordância com aquelas relatadas por Stuzin et al. ${ }^{7}$ e Caix et al. ${ }^{8}$.

A partir da análise dos dados obtidos no trabalho em pauta, pode-se afirmar que, embora o ramo temporal do nervo facial apresente uma ampla variação no padrão de sua ramificação, ele cursa em uma direção constante. Isto permite a definição de um plano de dissecção seguro para a região temporal, durante uma ritidoplastia temporal ou frontal. Os níveis de dissecção temporal podem ser definidos como sendo superficiais ou profundos ao ramo temporal do nervo facial. Esses níveis incluem: o plano subcutâneo, o plano abaixo da fáscia temporoparietal e o plano subperiostal.

A dissecção subcutânea deveria ser realizada superficial à fáscia temporoparietal, tomando cuidado para não confeccionar um retalho cutâneo muito fino, a fim de evitar lesões tróficas da pele e de proteger os folículos pilosos.

A dissecção abaixo da fáscia temporoparietal deveria ser feita na superfície da lâmina superficial da fáscia temporal profunda. Realizar uma cirurgia abaixo da fáscia temporoparietal implica em dissecar dentro da camada de tecido areolar frouxo subaponeurótico. Para a maioria das situações clínicas, esse é um plano cirúrgico seguro. É importante apreciar a espessura dessa camada areolar, e a dissecção poderá ser feita diretamente na lâmina superficial da fáscia temporal profunda, pois o tecido areolar possui um grau de espessura que permite a dissecção diretamente acima da fáscia temporal profunda mais facilmente do que ao longo da fáscia temporoparietal. Os ramos temporais do nervo facial são, em geral, mais anteriores e caudais ao ramo frontal da artéria temporal superficial, de modo que o risco de lesão é muito baixo, quando a elevação do retalho temporal é posterior a essa artéria. A elevação desse retalho deverá ser interrompida, quando a artéria é identificada visualmente ou pela palpação, a fim de evitar levar a dissecção para perto dos nervos temporais.

A dissecção subperiostal, utilizada na cirurgia de rejuvenescimento do terço médio da face, por via endoscópica, deverá ser realizada na superfície do arco zigomático. Para que o arco zigomático seja exposto, a dissecção deverá ocorrer abaixo da camada superficial da fáscia temporal profunda, dentro do coxim gorduroso temporal.

Vários autores ${ }^{1,4,10,13-15}$ citam o ramo frontal da artéria temporal superficial como referencial para a localização do ramo temporal do nervo facial. Constatou-se que esse ramo arterial é paralelo e superior ao curso do ramo temporal do nervo facial, emitindo sempre, ao nível da borda lateral do músculo frontal, um ramo descendente para esse músculo. Esse ramo arterial descendente apresenta uma íntima relação com as anastomoses nervosas extremamente finas do ramo temporal imediatamente antes delas penetrarem no músculo frontal. Esta importante relação anatômica, entre a porção distal do ramo frontal da artéria temporal superficial e os ramos terminais do nervo temporal, ocorre a $0,6 \mathrm{~cm}$ da borda lateral da órbita, em uma linha unindo o canto lateral do olho à raiz da hélice. Confirmou-se, também, em todas as peças dissecadas, a presença da veia sentinela próxima aos ramos distais do nervo temporal e do ramo frontal da artéria temporal superficial.

A veia sentinela e a porção distal do ramo frontal da artéria temporal superficial são marcos anatômicos fundamentais, pois indicam área vulnerável na proximidade do ramo temporal do nervo facial.

A ocorrência de sangramento nesta área resultará em um risco iminente de lesão ao ramo temporal, durante o processo de hemostasia. De uma maneira geral, as lesões decorrentes do uso de eletrocoagulação possuem um grande potencial de recuperação ${ }^{3}$.

Observou-se que as terminações do ramo temporal ao se aproximarem da borda lateral do músculo frontal assumem a disposição de um fino plexo semelhante a um leque numa extensão que varia de 1,8 a $4,2 \mathrm{~cm}$, verticalmente superior ao ligamento palpebral lateral. Embora o ramo temporal seja relativamente superficial na parte mais distal do seu curso, a sua penetração no músculo frontal sempre ocorre profundamente em sua face interna. Este importante relato anatômico é também referido na literatura ${ }^{3,12}$.

Idealmente, a localização dos principais marcos anatômicos relacionados ao nervo temporal deveria ser feita percutaneamente antes da cirurgia, de modo que a área contendo o nervo possa ser evitada ao se fazer uma incisão ou desenvolver um plano de dissecção.

\section{CONCLUSÃo}

Após perder a proteção da parte superior da glândula parótida 1,7 cm anterior ao trago, em geral dois ramos temporais do nervo facial cruzam o arco zigomático, no seu terço médio, e continuam em direção à região fronto-temporal, sempre junto à face profunda do SMAS, até penetrar no músculo frontal em sua face profunda. A observação da descrição anatômica durante o curso tridimensional constante do ramo temporal nas regiões zigomática e temporal, 
aqui referida, auxilia a prevenção de danos ao ramo temporal, fato que ocorrendo em muito prejudicará o pós-operatório na cirurgia de rejuvenescimento facial.

\section{REFERÊNCIAS}

1. Correia P de C, Zani R. Surgical anatomy of the facial nerve, as related to ancillary operations in rhytidoplasty. Plast Reconstr Surg. 1973;52(5):549-52.

2. Mitz V, Peyronie M. The superficial musculo-aponeurotic system (SMAS) in the parotid and cheek area. Plast Reconstr Surg. 1976;58(1):80-8

3. Baker DC, Conley J. Avoiding facial nerve injuries in rhytidectomy. Anatomical variations and pitfalls. Plast Reconstr Surg. 1979;64(6):781-95.

4. Ozersky D, Baek SM, Biller HF. Percutaneous identification of the temporal branch of the facial nerve. Ann Plast Surg. 1980;4(4):276-80.

5. Hinderer UT, Urriolagoitia F, Vildósola R. The blepharo-periorbitoplasty: anatomical basis. Ann Plast Surg. 1987;18(5):437-53.

6. Psillakis JM, Rumley TO, Camargos A. Subperiostal approach as an improved concept for correction of the aging face. Plast Reconstr Surg. 1988;82(3):383-94.

7. Stuzin JM, Wagstrom L, Kawamoto HK, Wolfe SA. Anatomy of the frontal branch of the facial nerve: the significance of the temporal fat pad. Plast Reconstr Surg. 1989;83(2):265-71.

8. Caix P, Goin JL, Modschiedler T. Le lifting facial profound par voie temporale. Ann Chir Plast Esthet. 1992;37(1):67-74.

9. Faivre J, Faivre JM. La place du lifting temporal profond dans lê traitement chirurgical du viellissement de la face. Ann Plast Surg. 1992;37:53-5.

10. Loeb R. Technique for preservation of the temporal branches of the facial nerve during face-lift operations. Br J Plast Surg. 1970;23(4):390-4.

11. Zani R, Fadul R Jr, Da Rocha MA, Santos RA, Alves MC, Ferreira LM. Facial nerve in rhytidoplasty: anatomic study of its trajectory in overlying skin and the most common sites of injury. Ann Plast Surg. 2003;51(3):236-42.

12. Yasargil MG, Reichman MV, Kubik S. Preservation of frontotemporal branch of the facial nerve using the interfascial temporalis flap for pterional craniotomy. Technical article. J Neurosurg. 1987;67(3):463-6.

13. Pitanguy I, Ramos AS. The frontal branch of the facial nerve: the importance of its variations in face lifting. Plast Reconstr Surg. 1966;38(4):352-6.

14. Stuzin JM, Wagstrom L, Kawamoto HK, Wolfe SA. Anatomy of the frontal branch of the facial nerve: the significance of the temporal fat pad. Plast Reconstr Surg. 1989;83(2):265-71.

15. Furnas DW. Landmarks for the trunk and the temporofacial division of the facial nerve. Br J Surg. 1965;52:694-6.
Correspondência para:
Maria Lídia de Abreu Silva

Rua Nossa Senhora de Lourdes, 65, apto 301 - Grajaú - Rio de Janeiro, RJ, Brasil - CEP 20540-370

E-mail: lidia7abreu@gmail.com 